Delft University of Technology

\title{
Transport Modes and Accessibility
}

van Wee, G.P.

DOI

10.1016/B978-0-08-102671-7.10402-6

Publication date

2021

Document Version

Final published version

Published in

International Encyclopedia of Transportation

\section{Citation (APA)}

van Wee, G. P. (2021). Transport Modes and Accessibility. In R. Vickerman (Ed.), International Encyclopedia of Transportation (1 ed., Vol. 5, pp. 32-37). Elsevier. https://doi.org/10.1016/B978-0-08102671-7.10402-6

\section{Important note}

To cite this publication, please use the final published version (if applicable).

Please check the document version above.

\section{Copyright}

Other than for strictly personal use, it is not permitted to download, forward or distribute the text or part of it, without the consent of the author(s) and/or copyright holder(s), unless the work is under an open content license such as Creative Commons.

\section{Takedown policy}

Please contact us and provide details if you believe this document breaches copyrights.

We will remove access to the work immediately and investigate your claim. 
Green Open Access added to TU Delft Institutional Repository

'You share, we take care!' - Taverne project

https://www.openaccess.nl/en/you-share-we-take-care

Otherwise as indicated in the copyright section: the publisher is the copyright holder of this work and the author uses the Dutch legislation to make this work public. 


\section{Transport Modes and Accessibility}

Bert van Wee, Delft University of Technology, Delft, The Netherlands

(c) 2021 Elsevier Ltd. All rights reserved.

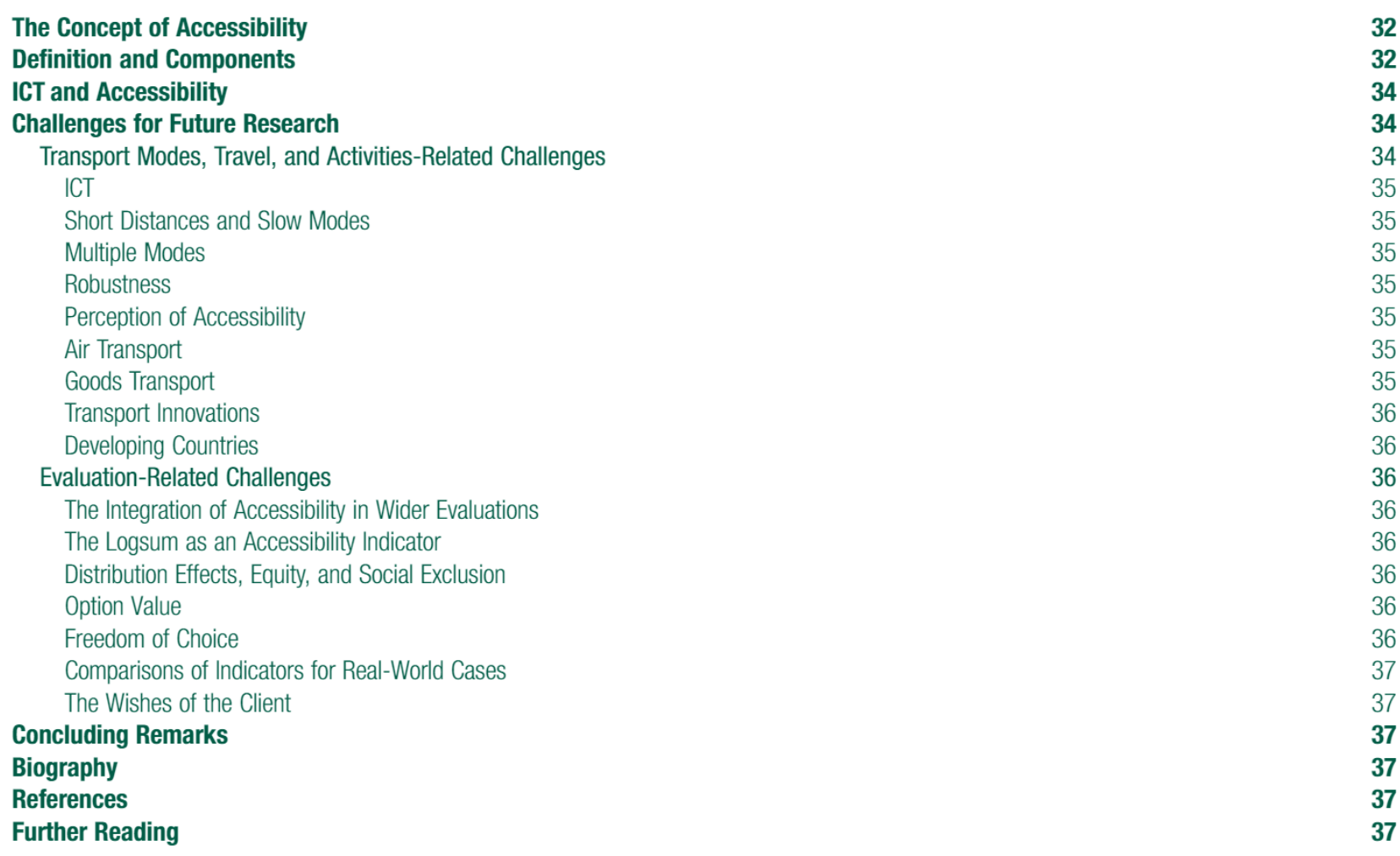

\section{The Concept of Accessibility}

Accessibility is a, if not: the, core concept in transport geography and transport planning. The transport system mainly aims to provide access to destinations of locations where people want to carry out activities such as living, working, education, shopping, recreating, and visiting other people. In case of goods, transport accessibility aims to allow companies to transport goods in different stages of production (from raw materials), via several intermediate stages to final (consumer) products, and (lastly waste materials) between locations (Geurs and van Wee, 2004). Briefly summarizing, it expresses the potential for interaction (Hansen, 1959; ElGeneidy and Levinson, 2011). Consequently, the main benefits of improvements in the transport system follow from providing access to destinations. Therefore, accessibility plays a dominant role in about all transport policy documents. But what is accessibility, how can it be defined, and which components influence final levels of accessibility? What is the state of knowledge, and which open challenges remain? This paper aims to answer these questions.

A main message is that multiple categories of indicators measuring accessibility exist, and that the choice between all those options depends on the purpose and context of the study. In addition, many research challenges could be a source of inspiration for researchers.

\section{Definition and Components}

The most downloaded paper in the Journal of Transport Geography is the paper on accessibility written by Geurs and van Wee (2004, p. 128) who define accessibility as "the extent to which land-use and transport systems enable (groups of) individuals to reach activities or destinations by means of a (combination of) transport mode(s)." Fig. 1 shows a conceptual model explaining which factors influence levels of accessibility. 

In line with Fig. 1, accessibility levels depend on four components:

- The land-use component (visualized as activity locations): the land-use system describing what is located where (e.g., jobs, other people, shops, health services, schools, and recreation facilities).

- The transport component (travel resistance): characteristics of the transport system determining how much time, money, and effort it takes to travel between locations.

- The individual component (wants, needs, abilities, opportunities, etc.) expressing what people need or want, and are able to do.

- The temporal component, expressing that it matters at which time which (locations of) activities are available. For example, shops and kindergartens have specific opening times.

The temporal component is not explicitly included in Fig. 1, but applies to all the other three components: people might have time restrictions, and activities transport services might be available during a selection of hours.

Fig. 1 shows that accessibility levels depend on the locations of activities, travel resistance, expressed in terms of time, costs, and effort, and the wants and needs of people. And those factors influence each other. As recognized by the so-called land-use transport interaction (models), land use influences the transport system and vice versa. For example, if residential areas are built adjacent to a railway line, a new station may be built along that line. And vice versa: locations near stations or motorway entrances and exits are relatively attractive for urbanization. The interactions between land use and transport also play a role at the level of individuals and households. For example, if new infrastructure is build, it reduces transport resistance, and that reduced resistance can make people change their residential location or destination choice. Characteristics of the transport system might influence people's wants and needs, for example, preferences to own vehicles, and the wants and needs of people might influence their residential location, and vice versa. Opening hours of locations that attract many people might influence timetables of a public transport system, and vice versa.

Almost all accessibility measures make use of one or multiple of the four components. Depending on the selection of components, these measures can be clustered in families of measures (Geurs and van Wee, 2004):

- Infrastructure-based measures, focusing on the level of service of the transport system. Examples are travel times to destinations, congestion levels on roads, and the number of stations accessible within a time or distance threshold (transport component).

- Location-based measures (also called place-based measures), focusing on access to spatially distributed activities. Examples are contour measures such as the number of jobs accessible from residential locations within a certain time threshold value. More advanced examples correct for distance or time using decay functions expressing that locations further away are valued less (transport and land-use component).

- Person-based measures, focusing on the individual level, such as the activities available for a person within time or other constraints. These measures originate from time, or time-space geography (transport, land use, individual, and temporal component) (Kwan, 1998; Neutens, 2010).

- Utility-based measures, expressing the utility that people address to the options of having access to spatially distributed activities, the so-called logsum being an important example. The logsum is the log of the denominator of a so-called logit model. This denominator includes the choice options available (transport, land use, and individual component; temporal component sometimes via time of day, but only partly).

The use of one or multiple accessibility indicators should primarily be based on the aim of the research and the options available. More specifically for a specific purpose the choice can be based on next criteria:

- The quality of the theoretical underpinnings

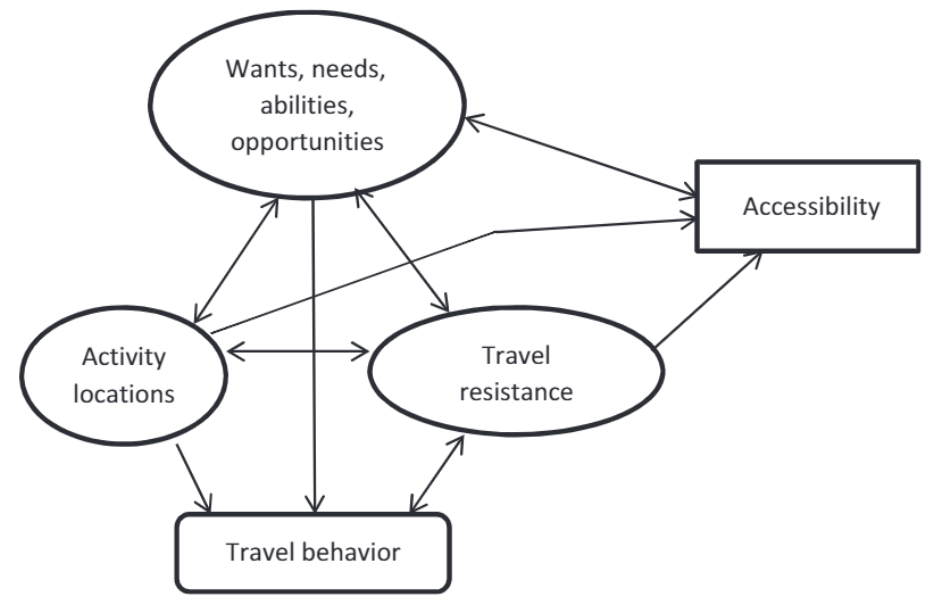

Figure 1 A conceptual model for accessibility, activity locations, and travel behavior. Source: van Wee and Geurs (2016). 

- The ease of operationalizing the indicators (availability of data, models, software, etc.)

- The ease of interpreting the indicators and communication results to clients of accessibility research

- The ease of including the indicators in evaluation frameworks like cost-benefit analyses (CBA) or multi-criteria analyses (MCA)

A dilemma exists because generally speaking easy to calculate and next communicate indicators (such as the number of jobs accessible within 45 minutes, or average speeds on the road or rail system) is theoretically less sound and can hardly be included in evaluation frameworks. On the contrary, the utility-based measures generally have theoretically sound underpinnings, but are difficult to calculate, certainly if a logit models-based transport model is not available, and communicate to many clients of research such as policy-makers (Geurs and van Wee, 2004).

\section{ICT and Accessibility}

Most of the accessibility literature only considers physical access to destinations. But increasingly information and communication technologies (ICT) provide alternatives, examples being skyping for personal communication, e-shopping, e-working, and elearning. So, to fully understand accessibility, in the future researchers and policy-makers should take notice of the relationships between ICT and accessibility. These relationships are quite complex, as visualized by Fig. 2.

Some examples of interactions are: because of the option to e-shops shops might relocate. Or congestion levels decrease if more people can e-work and therefore avoid the rush hours. It can also influence the wants and needs of people: they might consider access to shops or jobs less important if ICT-based alternatives are available. And people might be more inclined to multitask thanks to ICT, performing ICTbased activities while traveling by train being an example, and the option to multitask while traveling might reduce the willingness of train travelers to pay for shorter travel times. Therefore, the valuation of characteristics of the transport system might also change as a consequence. ICT might also relief time constraints, such as due to limited opening hours of shops. Not only does ICT provide alternatives for physical activities, it also can generate activities. For example, people might have met electronically and after some contacts they decide to meet in person. And due to ICT people might reorganize their activities over time and space. Next, ICT can also influence travel mode, departure time, and route choice, for example, because of the availability of real-time travel information.

\section{Challenges for Future Research}

\section{Transport Modes, Travel, and Activities-Related Challenges}

van Wee (2016) suggests several challenges for future research. The first category of challenges is content related; in other words, they focus on transport modes and activities.

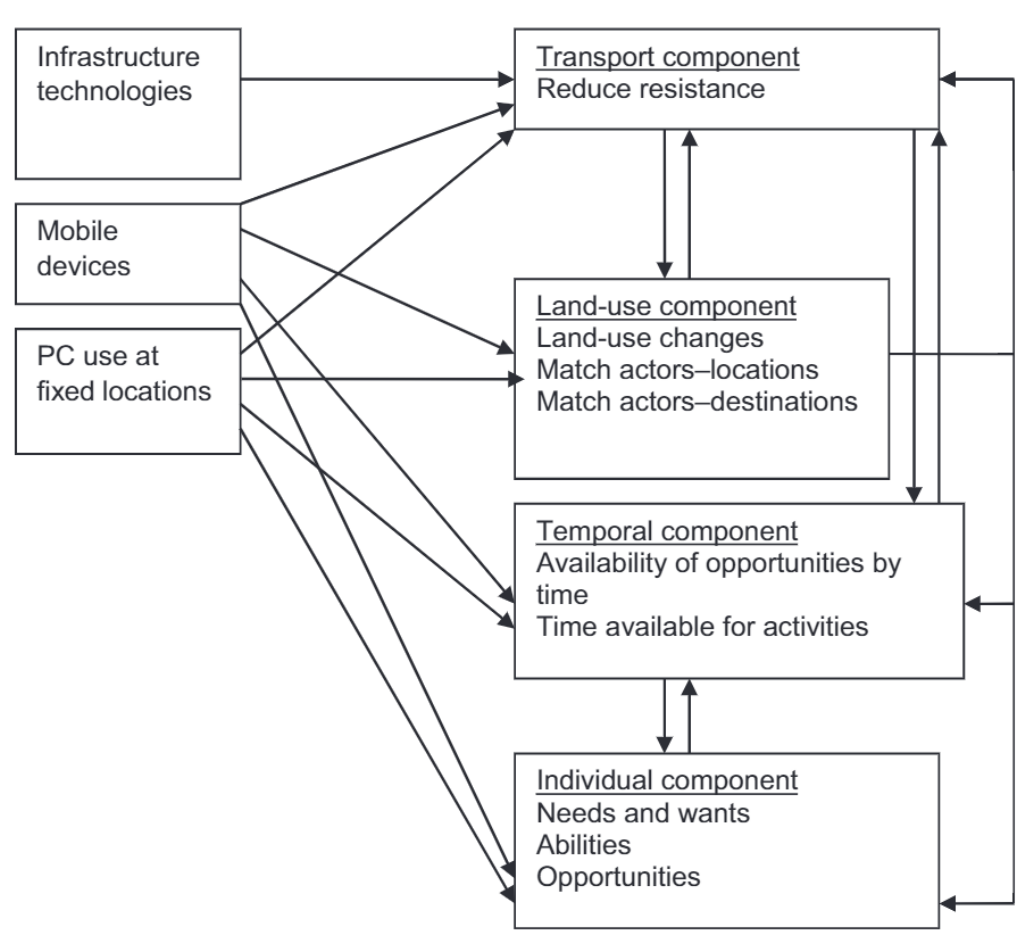

Figure 2 Relationships between ICT and accessibility components. Source: van Wee et al. (2013). 

ICT

The importance of ICT for accessibility is explained earlier. ICT can influence accessibility in many complex ways, as illustrated in Fig. 2. The accessibility literature so far has not, in a mature way, discussed how to include these links between ICT and accessibility in accessibility research. Such research should also include the dynamics in ICT options being available. One can think of advanced options to combine modes via Mobility as Service (MAAS) (information, ticketing, etc.), car and bike sharing, e-learning and eshopping options, etc.

In addition to including ICT in indicators for accessibility, this process will also generate new (big) data for accessibility analyses, via GPS-based data track and log systems, social media, and traffic flow-related data systems. A challenge is the assessment of the representativeness of these data because the use of related systems (e.g., social media) is not equally spread amongst the population. And early adopters of innovations might in some respects differ from the wider audience.

\section{Short Distances and Slow Modes}

The emphasis in the accessibility literature has largely been on longer distances and on car and public transport, often related to job accessibility. Active modes (walking and cycling) and nearby destinations have received much less attention, but can be very important for people, especially for having access to grocery shops, medical and other services, kindergartens, etc. Research in this area should include the specific context, for example, with respect to the quality of infrastructure for walking and cycling, and climate conditions.

\section{Multiple Modes}

People often combine modes to reach destinations, but the literature on multimodal accessibility is relatively underdeveloped. Furthermore, the fact that people can travel to destinations via multiple unimodal trips (e.g., either drive or cycle, or travel by public transport) is also often ignored in accessibility analyses. Additionally, for international trips people might positively value having available both aircraft and high-speed train options. The level of long-distance accessibility levels via these modes also depends on options to travel to and from airports and HSR station.

\section{Robustness}

Since the early 2000s academic literature has recognized the importance of related concepts like robustness, vulnerability, resilience, reliability, flexibility, and travel time variability. Using the term "robustness" as an umbrella term, it is important to recognize the different time scales at which robustness plays a role, ranging from short-term disruptions while traveling to several decades due to the impact of climate change on the transport system. And the relevance also differs strongly ranging from minor disruptions to disasters-related evacuations. A general challenge is to include robustness in accessibility indicators and next analyses.

\section{Perception of Accessibility}

Researchers generally calculate accessibility levels based on locations of opportunities, and characteristics of the transport system, and in some cases time constraint and personal characteristics (like car availability). But perceived accessibility, typically used when making choices, is seldom studied. Perceived accessibility can differ from calculated levels, for several reasons, the first example being that people might have misperceptions about the quality of nonused modes or opportunities. It can also be that they include additional characteristics of travel options, such as the attractiveness of the route or perceived social safety, or additional characteristics of opportunities, such as price and service levels of shops. The concept of perceived accessibility so far has not received a lot of attention, but for many people it could be more important than calculated levels of accessibility.

On a side note: in some literature perceived accessibility is sometime labeled as "subjective accessibility," and calculated accessibility as "objective accessibility." The terms "objective" and "subjective" are misused here, because measured accessibility does not perfectly reflect all characteristics of travel and opportunity characteristics, and subjective accessibility might include aspects that can objectively be assessed.

\section{Air Transport}

Overland transport (car, public transport, and, to a lesser extent, active modes) has dominated the accessibility literature. Longdistance transport, mainly air transport but also high-speed rail, has received less attention. But because of the rapid growth in long distance, transport accessibility by aircraft and high-speed rail is becoming increasingly important. In that area it is not only the direct and indirect (including stopovers) that matter, but also the frequencies, timetables, and prices. And it is important to include that frequencies are subject to diminishing returns: the higher the frequency, the lower the added value of a further increase in the frequency.

\section{Goods Transport}

Goods transport is an underexplored area in the accessibility research. It is way less studied in general, and also the importance of the concept, the decomposition between the accessibility components, and the choice of indicators are poorly understood, making it a challenging topic for research. Research in this realm should at least consider that goods do not "experience" travel, unlike people. 



\section{Transport Innovations}

The impact of innovations in the transport system (and ICT-see earlier) is poorly understood. Examples of innovations in the transport system include autonomous vehicles, MaaS, e-bikes, electric vehicles, and improved information systems such as those forecasting travel times. Note that ICT also contributes to Maas and forecasting travel times, and other ICT innovations can contribute to improved options to e-learning, e-shopping, and e-working.

\section{Developing Countries}

Most applications of accessibility literature focus on developed countries. Many challenges for accessibility analyses of developing countries exist especially due to the lack of available data. Maybe in the future this might change to some extent, because of the availability of big data for travel and activities of people. Another challenge could be that context matters. For example, the social status of modes can differ between countries, as well as preferences for activities (informal jobs, social ties, etc.) and social safety while traveling.

\section{Evaluation-Related Challenges}

The next category of challenges relates to the evaluation of accessibility levels.

\section{The Integration of Accessibility in Wider Evaluations}

Accessibility is not the only relevant topic for evaluations of (policies for) the transport and land-use system. An important question therefore is: how to include accessibility analyses in wider evaluation frameworks like CBA and MCA? CBA is the most common evaluation framework for at least transport infrastructure projects, but it is also often applied for other topics such as road pricing options. Because a CBA expresses anything that people value in monetary terms, accessibility indicators that express accessibility in monetary terms can relatively easily be included in CBAs. In all other cases, a major question is how to include accessibility analyses in CBAs.

In case of an MCA, results of accessibility can relatively easily be included. The main challenge is to come to adequate weight factors, relative to other important impacts of the transport system, like safety, several environmental impacts, investment, and maintenance costs.

\section{The Logsum as an Accessibility Indicator}

The logsum is an indicator that-under specific assumptions_can be used to assess the monetary value of accessibility levels. It is the $\log$ of the denominator of a discrete choice model, and that denominator includes travel options to opportunities.

But there are several challenges to further improve the logsum as an accessibility indicator. It ignores the fact that people value having multiple-choice options available, and-related-the love for variety in consumption. And it estimates the value of the decision, not necessarily the experienced utility. And the indicator is difficult to explain to nonexperts. Finally, the so-called IIA assumption of logit models can be violated due to autocorrelation, in case of destination choice.

\section{Distribution Effects, Equity, and Social Exclusion}

Accessibility indicators and accessibility studies generally ignore distribution effects and other equity-related issues (e.g., the fact that promises are made to a city or region), and levels of social exclusion. Since about 2010 (Martens, 2017), these topics have increasingly received attention of researchers, and consequently the inclusion of such topics in accessibility analyses will probably become more important in the future.

The challenge is not so much the development of indicators to study equity aspects of accessibility, because it can make use of indicators that are calculated anyway. And next these can be used to make explicit, for example, the distribution of accessibility levels over income groups or areas. A more daunting challenge is to include the indicators in broader evaluation frameworks, especially CBA. Another challenge is the underpinning of such indicators by ethical theories, although in recent years substantial progress has been made, dominant theories used being sufficient arianism, egalitarianism, and the capabilities approach. Another area for future research is the underpinning of quantitative yardsticks to label people of being socially excluded.

\section{Option Value}

People value available options, even if they do not use them. This is referred to in the (economic) literature as the option value (Geurs et al., 2006). For example, people might value of being able to travel by train, for the rare case of a roadblock, an event that might even never occur for them. The concept of the option value has seldom been included in the accessibility literature.

\section{Freedom of Choice}

People value being able to make choices, as expressed by the so-called concept of the "freedom of choice." So far the accessibility literature has hardly included this concept. It is partly related to the so-called option value (see earlier) but that concept only relates to the availability of options, not to the freedom to choose between options. 



\section{Comparisons of Indicators for Real-World Cases}

As explained earlier, many accessibility indicators exist, and choosing the "right" indicator for a specific study is not always easy because each indicator has its pros and cons. As explained earlier, there is a trade-off between the ease of communication and scientific quality. Comparing indicators for a specific application can be very relevant, first because it allows the researcher to find out how robust results are for indicator choices. Secondly, if complex indicators would lead to about the same conclusions as simple indicators, it could be an option to communicate the simple indicators to policy-makers and other clients of research, knowing that the results will be about the same if more difficult to interpret indicators would have been used.

\section{The Wishes of the Client}

Research studying what the clients of accessibility research need has hardly been done. In other words, we poorly understand the preferences of clients of accessibility analyses. Because a lot of accessibility analyses aims to support decision-making processes, it is an important avenue for future researchers to study those preference.

\section{Concluding Remarks}

Despite the fact that it is more than half a century ago that the seminal paper of Hansen about accessibility was published, the concept is still evolving, and there still are many definitions and indicators. In addition, several research challenges remain, not only because of weaknesses in current research, but also because society is changing in many ways, the impact of ICT being one important factor. This makes accessibility research an inspiring category of research, both for academics and for practice.

\section{Biography}

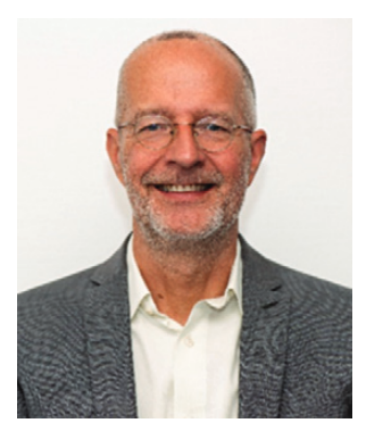

Bert van Wee is professor in Transport Policy at Delft University of Technology, the Netherlands, faculty Technology, Policy and Management. In addition, he is scientific director of TRAIL research school. His main interests are in long-term developments in transport, in particular in the areas of accessibility, land-use transport interaction, (evaluation of) large infrastructure projects, the environment, safety, policy analyses, and ethics.

\section{References}

El-Geneidy, A., Levinson, D., 2011. Place rank: valuing spatial interactions. Netw. Spat. Econ. 11, 643-659.

Geurs, K.T., van Wee, B., 2004. Accessibility evaluation of land-use and transport strategies: review and research directions. J. Transp. Geogr. 12, 127-140.

Geurs, K., Haaijer, R., van Wee, B., 2006. Option value of public transport: methodology for measurement and case study for regional rail links in the Netherlands. Transp. Rev. 26, 613-643.

Hansen, W.G., 1959. How accessibility shapes land use. J. Am. Inst. Plan. 25, 73-76.

Kwan, M.-P., 1998. Space-time and integral measures of individual accessibility: a comparative analysis using a point-based framework. Geogr. Anal. 30, 191-216.

Martens, K., 2017. Transport Justice: Designing Fair Transportation Systems. Routledge, New York/London.

Neutens, T., 2010. Space, Time and Accessibility—Analyzing Human Activities and Travel Possibilities from a Time-Geographic Perspective. Department of Geography, University of Gent, Gent, Belgium.

van Wee, B., 2016. Accessible accessibility research challenges. J. Transp. Geogr. 51, 9-16.

van Wee, B., Geurs, K., 2016. The role of accessibility in urban and transport planning. In: Bliemer, M.C.J., Mulley, C., Mouton, C.J. (Eds.), Handbook on Transport and Urban Planning in the Developed World. Edward Elgar, Cheltenham.

van Wee, B., Geurs, K., Chorus, C., 2013. Information, communication, travel behavior and accessibility. J. Transp. Land Use 6, 1-16.

\section{Further Reading}

Handy, S.L., Niemeier, D.A., 1997. Measuring accessibility: an exploration of issues and alternatives. Environ. Plan. A 29, 1175-1194.

Páez, A., Scott, D.M., Morency, C., 2012. Measuring accessibility: positive and normative implementations of various accessibility indicators. J. Transp. Geogr. $25,141-153$.

Witlox, F., 2015. Beyond the data smog? Transp. Rev. 35, 245-249. 
